\title{
Urgences
}

\section{Le ruban...}

\section{Céline Bouchard}

Numéro 13, mars 1986

\section{Éclats d'atelier}

URI : https://id.erudit.org/iderudit/025211ar

DOI : https://doi.org/10.7202/025211ar

Aller au sommaire du numéro

\section{Éditeur(s)}

Urgences

\section{ISSN}

0226-9554 (imprimé)

1927-3924 (numérique)

Découvrir la revue

\section{Citer ce document}

Bouchard, C. (1986). Le ruban... Urgences, (13), 31-33.

https://doi.org/10.7202/025211ar

Ce document est protégé par la loi sur le droit d'auteur. L'utilisation des services d'Érudit (y compris la reproduction) est assujettie à sa politique d'utilisation que vous pouvez consulter en ligne.

https://apropos.erudit.org/fr/usagers/politique-dutilisation/ 


$$
\square
$$




\section{Postulats: mesure et homosyntaxisme}

Écrire un texte qui contienne, côté mesure, des verbes $(\mathrm{V})$ de trois syllabes, des substantifs (S) de cinq lettres et des adjectifs (A) de six lettres disposés, côté homosyntaxisme, selon l'ordre suivant: SASVSSAASVSAAASVSVSSSSSSSASVVASAASVSSAASVSVSSVSSVSWVWVSSSSAAVSASSASSSSSAVSVAVAVASSVSSVSSASVSAASASASS'.

Mesure et homosyntaxisme - voir Oulipo: Atlas de littérature potentielle, p. 227 et ss., 159 et $s$.

1. L'ordre en question, qui doit être proposé sous cette forme, est celui des VS A des vingt et une premières lignes de la section "Ordre" (I) de l'introduction ("Comment est fait ce livre") des Fragments d'un discours amoureux de Roland Barthes, coll. "Tel Quel", Paris, Seuil, 1977, p. 10-11. Ce n'est qu'après l'exercice que ces coordonnées sont données. 


\section{Céline Bouchard}

le ruban violet du jupon s'enroule autour du corps

la ville sombre dans le serein matin assouvit la terre chaude et muette les douces peurs surgissent avec l'ombre nourrissant le songe des pères et le coeur des sages

les vases de roses dans la salle argent du géant recouvrent et colorent admirablement la petite table la grande et lourde porte s'entrouvre sur le temps et les vents rieurs un triste pleur s'écoule sur la vitre je regarde les jours et les nuits qui s'éclairent des lunes

le sacré envahit le germe qui s'éveille se transforme et se découvre forcément je m'inquiète je m'épeure des dieux et des héros sur la route de sable safran et orangé je projette la roche lourde sur l'amant et l'époux jaloux

voici la forêt et l'arbre voici la fleur et la pomme voici la pluie claire qui humecte les joues je recule muette je m'arrête subitement et j'invente le triste conte

le nuage promène les rêves du monde je m'essouffle sur la plage des mères naïves le crime enfouit dans le désir furtif la grande place pleine de faces le pauvre livre la gerbe de lilas mauves et l'amour s'entachent éperdument sur les corps d'émois

les jeunes et jolies baies s'étendent sur les ondes rouges vertes et bleues

les chats dégustent le fruit qui les enlise peu à peu 